\title{
J
}

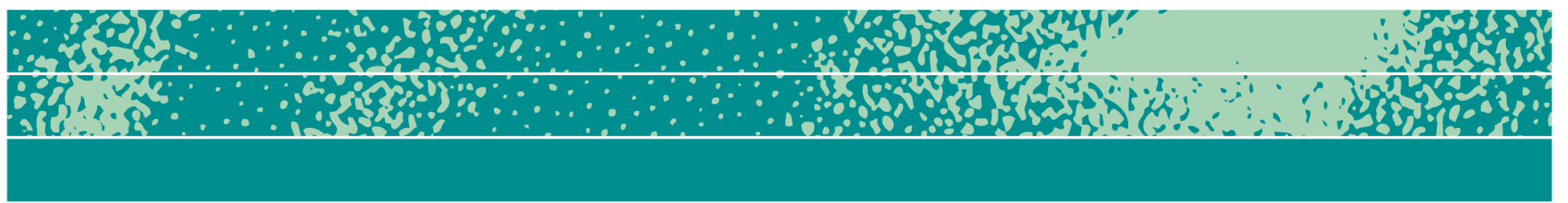

\section{Personal Printers and Ink in São Paulo and Recife: Getting New Things Done}

\author{
Ken C. Erickson
}

\begin{abstract}
Team ethnography for a desktop printer manufacturer in two Brazilian cities on desktop printers and printing is reported here. Our team aimed to resolve an initial puzzle about printers and ink and explored what was going on with the desktop printers as they were acquired, used, and maintained. Our work expanded to encompass the LAN house, small shops, often operated by entrepreneurs, that provide access to the Internet and to printing. The research led to an intrapreneurial modification of a long-standing desktop printer business model by the client. The article concludes by exploring how entrepreneurs (shop owners and teams doing ethnography for hire) and intrapreneurs (those who venture from within a large enterprise) widen the scope of their venturing to encompass wider social and political issues like moral panic, poverty reduction programs, and building social capital in low-income communities in the course of entrepreneurial venturing.
\end{abstract}

\section{Key words}

desktop printers, ink, consumer ethnography, Brazil, itinerary method
Page 1 of 25

JBA 8(2): 273-297

Autumn 2019

(C) The Author(s) 2019

ISSN 2245-4217

www.cbs.dk/jba 
The story of methodology is the story of the study. -Michael Agar

\section{Breakfast in São Paulo}

"Não" (No) said the white-shirted waiter behind the U-shaped counter at AJ, a bakery café near the center on São Paulo. "Não," the waiter shook his head at me.

“Ágente precisa..." (We need to...)

We need to what? I was missing a step, that was clear. What was it that he needed me to do? My Portañol (Portuguese-Spanish) failed me and I was craving coffee, and breakfast. I would meet my field teammates, Sara and Taís, later in the morning of my first visit to Brazil, a visit in the Southern winter of 2010 designed to unpack a puzzle and document the consumer points of view within Brazil's emerging middle class, by focusing on desktop printers. I had been warned by more than one Brazilian friend that while my Spanish might be understood, it might not be especially welcome in Brazil. Nevertheless, I carried with me a misplaced expat conceit that I'd be able to at least negotiate breakfast. No womb-like hotel basement for me! I'd venture out to the edges of the upscale Jardins neighborhood and find out where the locals were having breakfast.

Finding a local spot for breakfast was easy enough but getting that cup of coffee was not. My delight (and pride) at escaping the business hotel turned out to be hubris derived from my misplaced assumption that several years of work in Chile and visits elsewhere in Latin America over the previous thirty years would lead to a smoothly accomplished and locally sourced breakfast. I'd identified a bakery café. I'd found a seat and I'd seen and smelled the steaming - what were they, cortados? Lattes? My nose was teased by the aroma of freshly baked I-knew-not-what behind the U-shaped counter. I'd been watching other customers enjoying some round bread things - but what? I was unable to sort out ordering and I did not know what to ask for.

How to meet and greet an executive, how to politely exchange business cards, and what local expectations might be around gifts among business clients, international managers, or government officials are often the stuff of entrepreneurial training in business schools. But quotidian spaces surrounding everyday life, café breakfasts included, are rarely encompassed by the academic gaze of business researchers. Competence in those worlds is learned and demonstrated in the café and on the street. Studying the products that people acquire and use on behalf of the global corporations that make and market them might be expected to rely on an understanding of the economically rational and rigorously manageable regularities of buying and selling. Ethnographic study for or within enterprises tells different stories (Tett 2009; Hertz 1988; Moeran 2004). 
Doing research with consumers on behalf of consumer product companies has convinced me that not all business folk view what people do with products as simply transactional, economically rational, or easily measured. This article reports on such a venture: a study of desktop printers among Brazil's emerging middle class in two cities. It also includes a quite unexpected follow up study, in the same two cities and involving Brazil's emerging middle class. This study included venturing, "getting new things done," the phrase Shumpteter (1947: 152) used to encapsulate entrepreneurship. That second aspect of this article brought to light multiple entrepreneurial activities and players, all venturing around desktop printers.

\section{The Research Venture}

Differences of opinion among marketing staff are often found in ethnographic reports of work with and for consumer-product companies (for example, Briody and Erickson 2017; Karsten 2019). Marketing staff on the front lines of research may have different views than those of higher-level managers. Those in the C-Suite (the top floors of the corporate offices) may be more focused on opportunities that are quantifiable and easy to exploit. Linear approaches to the pre-purchase intentions and purchase processes that can be mapped, captured in segmentation schemes (Sunderland and Denny 2011), or sorted into decision trees seem more convincing to the internal corporate funders, whose interests are said to focus on quarterly numbers for market share or product line profitability. Skills at breakfast in an unfamiliar language in an unfamiliar place may not be part of the business school curriculum, but in a way, it was part of the consumer electronics project offered to the likes of our little team. Our corporate client-one with a history of careful market entry and a long-range, non-quarterly-report focus-wanted to understand the details of every-day-life that surrounded the desktop printers and ink they made. The manufacturer wanted to understand how its products were (or were not) being purchased and used. It hoped to use what was learned to adjust its marketing plans for desktop printers and the ink sold for them.

As our team members had done before when working with consumer products, we built our field plan around a theoretical approach derived from Dominique Desjeux's itinerary method $(1994,2004,2015)$. Desjeux considers this approach both a theory and a method (a distinction that maybe fruitful when writing for an academic audience but in my experience, hardly a distinction of importance when doing ethnographic work where theory and method are entangled in a bricolage of iterative in-field analysis by team ethnographers). The itinerary method points to what ethnographers should look for, where, with whom and when. 
Prior to fieldwork, the itinerary method suggests where to go and what to look for. During the iterative analysis that happens in the field, the itinerary method offers guideposts for analysis, directing fieldwork teams to attend to the daily-life practices of talking about or doing things with consumer goods, following objects as they move from vendor to home. Along the way, a list of categories of social life- like gender, age, class, level of education and taste-may become visible as goods move along their itinerary. Think of output from desktop printers, for example. A printed resume may embody all the categories in that incomplete list.

Echoes of Nancy Munn's notion of value transformations among the Massim (1988) are always within earshot when learning about relationships between consumer goods and people. A desktop printer's value transforms as it moves through its itinerary. In other words, the desktop printer means one thing to the company's team of marketers and packaging-designers, but means other things to the salesclerk, the purchaser, and a 15-year-old printer user. For ethnographers who do work for hire, thinking about value transforms as part of a paid engagement becomes a value transform, itself. A team of entrepreneurial ethnographers borrow a theory from the literature (or from an academic practitioner met at a conference) and make it a part of the exchange system between its business venture and a client, thereby transforming a theory into research plans.

Desktop printers are not the only things moving about in social systems here. Paper and ink (called "consumables" in the trade) and what the consumer electronics industry calls peripherals are added to the social object to make it an assemblage. With the assemblage in place, people print documents and images, share them, move the assemblage and its elements about, maintain it, break it, deal with the ink running out or perhaps put the assemblage on a storage shelf where it may collect dust and mildew, and become inoperable. We tried to be present-with people and with desktop printers-for as many of those moments as we could. The team was on the lookout for value transforms along the desktop printer itinerary.

In one of our initial meetings, the client initially identified a puzzle - a rich point—based on its sales data: people were buying printers, but not the ink, despite the fact that the company had import/export data that showed lots of desktop printer ink coming into Brazil. Unpacking that rich point, and our related research, provided the client a new opportunity, a new target market, and an additional research opportunity for the ethnographers. In this way, entrepreneurial activity is threaded through this story, as ethnographers, research participants, and corporate clients "getting new things done" (Schumpeter 1947:152) in response to a new or unrecognized opportunity.

More on all that in a moment. First, I have to figure out that 
elusive morning cup of Paulista coffee.

\section{Our Research Brief: Desktops on a Rack}

That first morning in São Paulo, my puzzled looks and the lack of a productive engagement with the waiter behind the counter were noticed by the cashier. She came out from behind her counter and guided me gently to the caixa, the electronic cash register on the counter at the entrance. As is the case with many small shops in the city center of São Paulo, there was no door, just an opening to the street with a roll-down security door. It was a very cold morning. The cashier was bundled up in a winter jacket. She pressed a plastic card with a barcode and number on it into my hand, a card which the waiter would scan, then enter my selections on a keyboard. I asked for coffee, pointed at what I soon discovered was a welcome, warm, pão de queijo (cheese roll) and soon enough I was adequately caffeinated, nourished, and ready to meet my Brazilian research colleagues. Thus, compassionate sociability made a workaround for my lack of technical awareness of Brazilian point-of-sale technology and my lack of linguistic skill in the breakfast department. This breakfast set the stage for the work, as our clients wanted our team to explore the worlds of meaning-technical and affective- that might be discovered around desktop printers.

After breakfast, I met Taís Pavez and Sara Azevedo in my hotel lobby. They were ready with their lists of recruited families, recruited according to their membership in the lower-middle class segment of households in our two target cities, São Paulo and Recife. Tessa Jones, our US-based videographer-ethnographer who Sara and Taís had dubbed Jones da Silva, joined us, too.

We discussed how we would be shopping along with some of the respondents, those who were interested in a printer but did not have one, with money provided by our manufacturer client. Sara and Taís walked Tessa and me through our local travel plans and schedules. Working in lower income communities across São Paulo presented special challenges. We would have to move through world-class traffic jams, transit through or work within neighborhoods that upper-class Brazilians (some of whom were among our client's team) avoided and seemed to know only through sensational news reports of youth violence and drug cartels.

Our team of women researchers were already familiar with the territory. They came equipped with plans to avoid the worst traffic, a plea for schedule flexibility and recommendations about distinguishing real from imaginary safety issues.

Taís and Sara, with Sara leading the recruiting, had found and met with people from 15 households from central and suburban São Paulo, all with incomes ranging from $\mathrm{R} \$ 400$ to $\mathrm{R} \$ 3,100$ (\$96-743) monthly- 
extended households, nuclear families, and a mom with a new baby. Not a big sample, but a good range. There were also eight households to interview later in Recife, Pernambuco. We'd visit those households as well (See Figure 1).

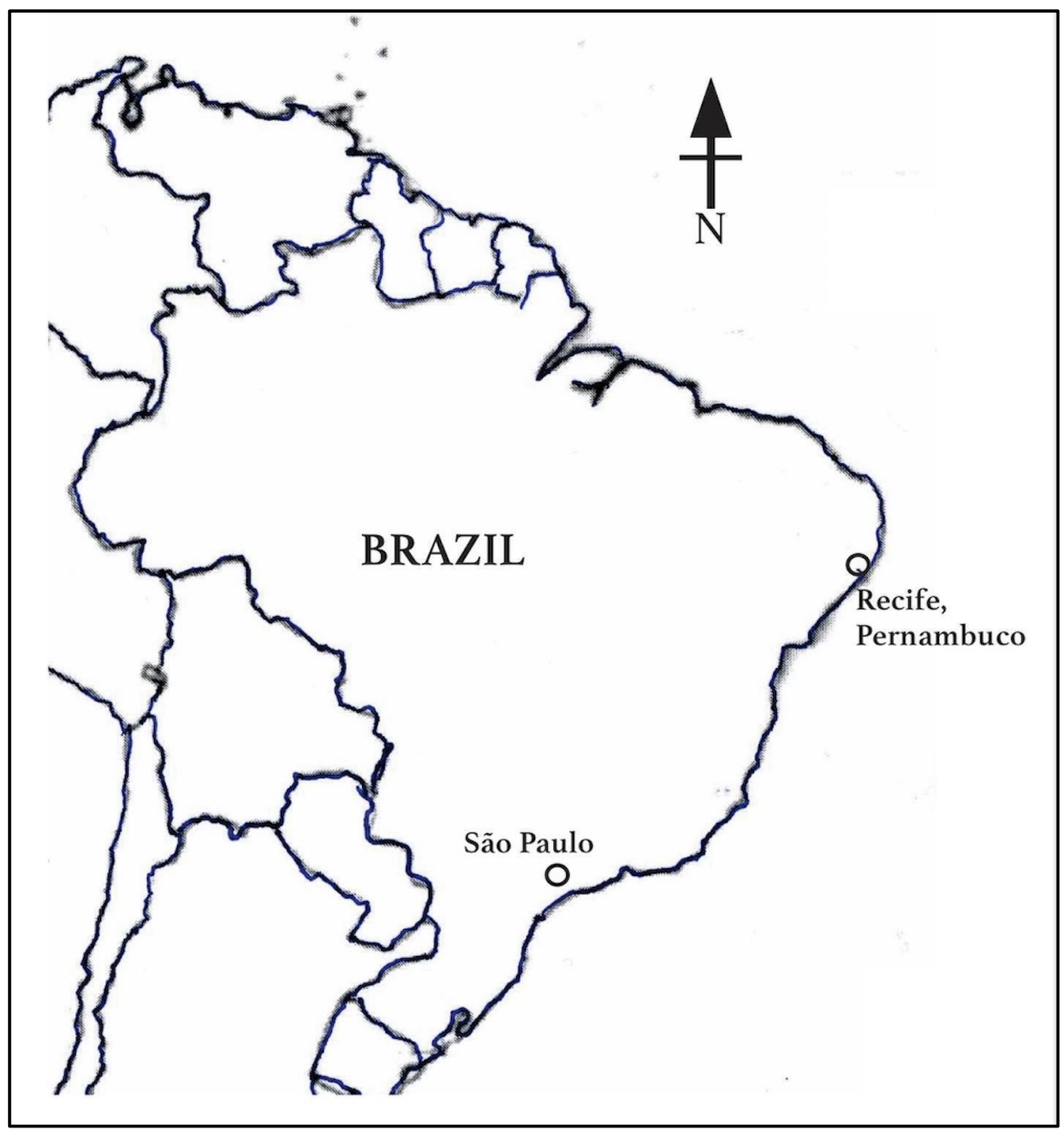

Figure 1. Field Locations in Brazil

The corporate effort to understand the place of printers and printing within Brazil's so-called new middle class was in our view (and in the view of our client) inseparable from the Lula (Luiz Inácio Lula da Silva) government's response to the deep and tenacious poverty experienced by many Brazilians. At the time of our work, Lula's successor, Dilma Rousseff, wore the presidential sash. Lula's responses to Brazilian poverty included the Fome Zero (Zero Hunger) program, and within it, the income transfer program for families with children called Bolsa Família (Family Purse), which most researchers agree played a significant role in lowering infant mortality and raising incomes (Victora et al. 2011).

Despite the continuation, for some, of the grinding poverty and suffering that Scheper-Hughes (1993) documented in Pernambuco from the 1960 s to the early 1990s, and despite both ideological and 
operational criticisms, Fome Zero and Bolsa Família had helped create a growing middle class in Brazil that allowed many Brazilians to act out new dreams of middle class life (Mújica et al. 2010). Brazilians were buying computers and, perforce, personal printers. A fairly stable period of economic growth, despite the 2009 global recession, was also part of the reason for the intensified interest in Brazil's new consumers by manufacturers like our client.

\section{A Post-Crisis Rich Point}

After the global financial infection that began with the collapse of the U.S. subprime mortgage market (Tett 2009), Latin America generally, and Brazil in particular, were doing pretty well from the point of view of international business organizations. A team of World Bank economists charged with explaining Brazil's relative success in responding to the great recession of 2008-2009, said that the country "has been able to avoid a deeper economic downturn and to quickly work its way through the global crisis" (Blanco et al. 2011:135). Average cumulative GDP growth in Latin America was slightly more than double that of North America from 2008 to 2014: 42.44 percent versus 22.65 percent (Arias and Wen 2011:11).

Household income status was in better shape under Lula (Ribera, Currais, and Renga 2009). Fewer people were living in abject poverty and fiscal adjustments were being made that were improving the global financial system's general view of Brazil for the better (Suares, Ribas and Osório 2010). Department stores like Lojas Americanas and Casas Bahia were expanding, offering consumer goods-washers, televisions, computers and desktop printers-with easy in-store credit to low-income wage earners, the "new" members of the so-called C classes in Brazil. Desktop printers, the company told us, were usually sold with a computer, printer, keyboard and mouse as part of a bundled deal. It was not surprising that our printer manufacturing client told us that the company was focusing more marketing attention on "Latin" (company argot for Latin America). Latin American purchasing power was growing and with it a need to understand more about potential customers for the company's line of desktop printers.

Brazilian ink cartridge sales for these printers presented the company with a rich point. Rich points are puzzles, the product of a crosscultural (and in this case also cross-national) divide that calls for some bridging between "languicultural" worlds (Agar 2013: 175).

Our client was among the market leaders in Brazil. Middle class Brazilians were buying the company's printers but not the company's ink cartridges. Since the introduction of ink jet technology into the personal printer market in the 1980s, manufacturers had adopted the so-called "razor and blade" business model: sell the basic tool at or near cost, sell 
the supplies at a significant markup. The U.S. consumer product testing organization, Consumer Reports, recently pegged printer ink at about $\$ 50$ dollars/ounce, which works out to $\$ 6,500$ per gallon (Bufete 2018). Ink cartridges were expensive, and users like our ethnographic team knew it. Could it be that printers were simply gathering dust in Brazilian households? That seemed a possibility, but after digging through Brazil's tariff data, the printer manufacturer found that Brazil was importing a lot of inkjet printer ink, most of it from Korea. That was the puzzle! Who was buying that ink? Who was printing? Brazil as a whole was buying a lot of ink but not the ink that the company expected its customers to buy and use with its products.

The company wanted to understand how (or if) households in Brazil were actually using printers. In the process, we-and the company-hoped to figure out where all this ink was going.

\section{The Puzzle That Wasn't}

Taís and Sara already had a solid grounding in the social, political, and economic lives of ordinary Brazilians. The political scientist Taís and her market researcher colleague Sara had collaborated before on consumer product research among lower- and lower-middle class households in Brazil. Early on during a telephone meeting, a possible solution to the company's rich point came to the surface:

"People aren't printing at home," said Sara. "They're printing at the LAN house."

The LAN house is a shop where people can use computers, access the Internet, and access other computer-related services; LAN house stands for local area network.

Local researchers with experience on the ground can often work out answers to what seem, from the perspective of a distant corporate client, to be intractable puzzles. Locals have access to contexts that distant corporate managers may not. Sometimes, the realities of consumers' worlds might as well be thousands of miles away from the daily lives of product managers, even though their offices may be just down the street from their customers. This point is another way of saying that those at the bottom of the ladder (including lower-middle class Brazilians and those who make their livings learning about them) have to do more interpretive labor, and must know more about the local context on the ground, than those at the top of the social ladder whose lives are insulated from other people's life worlds. This situation can lead to what Graeber (2015) has pointedly called "stupidity" on the part of high-level managers and bureaucrats. Distance is not just about geography. In Brazil, with marked residential and work segregation by income and class, it was not surprising that some of the managers at our client's Brazilian offices 
found this $L A N$ house suggestion unconvincing, even though there are hundreds of LAN houses in São Paulo.

Along a manager's daily commute from a relatively high-income part of town to the company's Brazilian offices, the LAN house existed only as part of the upper-middle class imaginary about the Brazilian lower-middle class. Some of those managers lived not far from my breakfast place in Jardins. These managers generally do not see a $L A N$ house unless their cars are driving at street level in a lower-income neighborhood. (And as we were to discover, a LAN house may be hidden in a public housing complex without outwardly visible signs marking its presence).

Not only that, but LAN houses were liminal places according to popular, normative discourse in Brazil at the time. They were not places where nice people (of whatever social class) were generally expected to hang out (Nemer and Reed 2013). Not unlike the contemporary Wang Ba (internet café) in China (Fauna 2014), the LAN house was thought to be a place inhabited by disorderly young men smoking cigarettes, playing video games, and otherwise misbehaving online. It was a focus of a kind of moral panic, even a political sign for some. For example, legislation in Brazil at the time had pushed for LAN houses not to locate near schools as they were thought to encourage time wasting and bad behavior by lower income boys.

The possibility that the LAN house could be a way to reduce inequality of Internet access, while evident to some academics and social reformers, was not always recognized as an acceptable strategy to counter unequal access to technology (de Araujo, Reinhard and Cunha 2018). While at least one manager at the company's São Paulo office wasn't buying it, we were given scope to bring some field data to bear on this and other questions about personal printer use among the people that our client initially wanted to learn more about.

\section{Sampling, Carrot Cake, and Very Good Boxes}

Our ethnographic sampling process involved using the networks that Sara had already established in her market research work, plus a bit of serendipitous hanging around in places where we might meet and talk to people who were involved along the desktop printers and ink itineraries. We followed local practices to define what we meant by "emerging middle-class households," using local marketing nomenclature (and following our client's lexical lead) to label household classes from A to E. These categories do not use economic criteria alone to define social class. Instead, Brazilian market research practice identifies these segments based on national-level surveys that identify the relative absence, presence, or quantity of nine attributes: bathrooms, radios, televisions, automobiles, VCR/DVD players, washing machines, freezers, education of 
household head, and household helpers, with a point scale assigned to each based on the number of each of those items belonging to the household (ABEP 2008). Interestingly, smartphones, Internet access, and computers were not then part of the standard list. Our team sought Cclass households with computers but included four households in São Paulo and two in Recife that had computers but no printers. We provided a cash incentive to all participants, and an additional cash gift to two of the non-printer households in São Paulo. These families were encouraged to buy a printer and computer of any brand. We chose non-computer households in which a family member seemed especially open to shopping along with us, enabling the team to participate in the prepurchase and purchase experiences directly.

Our client-side colleagues and our own team wanted to incorporate visits to households in both urban and peri-urban São Paulo, as well as visits to Recife in the North East. Recife, and indeed the entire Northeast, had been among Brazil's poorest regions. But beginning about 2005, Pernambuco state was significantly outpacing the rest of Brazil in economic growth (Santos 2014). It was an attractive market for computers and desktop printers.

Sara and Taís had already begun their home visits by the time we met after my breakfast. Tessa and I were coming in toward the end of their interview process to film printer use and conduct additional inhome visits with some of the households. By then, we knew that Sara's idea, the notion that the LAN house was the place where most people were doing their printing, had been well established.

Home visits often began at kitchen tables accompanied by coffee and cake, eventually including a tour of the spaces where computers and printers were used. Once, after finishing a slice of carrot cake in a Paulista neighborhood (the third carrot cake of my sojourn), we were shown the household computer rake. The rake is the typical computer table with a shelf above the desk where a printer rested, usually watched over by one or more framed images of saints or family members; these images attached to the wall or shared shelf-space next to a printer.

This rake belonged to a married couple, living with their teenage daughter, Francesca. The mom said her daughter used the machine whenever she wanted to but her mother was careful to monitor what she accessed online-hence, she explained, the rack residing in mom's bedroom (although mom barely knew how to use the machine). Francesca browsed around in her computer for us, looking for something to print, selected a document, but found that the printer was out of ink. Francesca removed the cartridge, placed it on a paper towel, and shook it. Still some ink inside-but evidently not enough. So, what to do? Buy a new one? No need, she said.

A block away, we were told, was a storefront that could do a refill. 
Sara and I joined the young woman on a walk up the street. Tessa followed along with her video camera while Sara asked Francesca if she felt safe walking alone to school on dark winter mornings. (She said she did, except that traffic accidents were a problem which she judged were "normal.") She stopped beside a storefront open to the street, a store with a plastic banner above the entrance: Assistência Técnica Especializada em Impressora (Technical Assistance Specializing in Printers). She handed the cartridge to a young woman who was working behind a glass display case that held used printers and some new printer cartridges:

"When will it be ready?" and "Can my mom come back and pick it up?"

A receipt was written out by hand, destined for Francesca's pocket and later the kitchen table. We walked back to the house to look over some printer output that her mother had laid out on the kitchen table. Among them was a black-and-white birthday banner to which Francesca had been adding colored pencil flourishes, designed for her upcoming birthday party, all arranged for us to look at when we returned from the refill shop.

The household pattern that emerged from visits like this were clear enough: only one household, the one with the highest income among our São Paulo sample, actually used original cartridges - the ones sold by the printer manufacturer. Among other households, when cartridges ran out, they were refilled just as Francesca had done. LAN house printing was the choice for color printing or for printing multiple pages. Thirteen of the 27 households had done no refilling (and bought no new cartridges) in the past year, the same number that had owned their printer for less than a year.

Here, for example, is what Amélia told us. She is another young woman who, like Francesca, was in charge of household printing. She lived in an urban São Paulo neighborhood near the center of São Paulo. What she told us illustrates that young women in such households are well aware of printing costs:

Taís: Do you print photos?

Amélia: Not often. But sometimes my mother sees a photograph from when I was little, with my friends. She's [saying] 'print! print!' Then I'd tell her, 'No, mom! It takes a lot of ink! Because it's all in color!'

Our team was not too surprised by the ways in which these households were printing, nor was it surprising to find adolescents managing computers and their Internet connections. There was, for example, the apartment in Recife where two teenage brothers ran cables to their cousin's apartment, through the trees in the courtyard between buildings, to reach their relative's Internet router so they could access the 
Internet from their own bedroom rake.

There were other patterns and themes that our team discussed over dinner after our field visits but that were not likely to be of great interest to our client - or so we thought. Patterns like the assemblage that surrounded the printer - the power stabilizer; the mouse and keyboard; the computer and monitor; the rake, or small computer desk - had been acquired by all but one of our printing households. And one other item was sometimes kept near the printer: the printer's original packaging:

Amélia. We have everything here. The box, the printer box, the box for the stabilizer. We have the box from the keyboard and the mouse. We bought them separately. Just in case there is a problem, we have all the boxes and everything inside, the foam packing.

Amélia's Mom: We've saved all the pieces. Everything is well preserved. it was something hard to buy. We'd rather things stay here. But if we move one day, we have the boxes and we saved the other things. So, it's good to have these boxes, especially these, these very good boxes.

We had thought that the information on packaging might be of interest only insofar as it related to the process of unboxing and setting up a printer for the first time. We had attended to the unboxing process of our respondents with whom we had shopped for a printer because it was part of the printer's itinerary and because unboxing was a frequent focus for product designers (Kim, Self and Bae 2018). Designers (and, these days, online product reviewers) attend to the process of unboxing and setting up a piece of consumer electronics to understand or guide the customer's "out-of-box" experience. In this case, we later learned that our key contact at the printer manufacturer had been working to convince his colleagues of the more general importance of a high quality box that would signal the quality of the product inside and also provide space for text and print messaging for communicating at retail. Our evidence of the importance of the box as a valued post-purchase element, we were told, would later help leverage the manager's efforts to resist a C-suite push for cheaper packaging.

\section{Into the LAN house}

From the very start, our attention in São Paulo had been drawn to the $L A N$ house as an important site of printing. What we saw corresponded to the academic work on the LAN house, perspectives that saw in these enterprises a way to provide Internet access and computer literacy to bridge Brazil's “digital divide" (da Silva and Gushiken 2010; Nemer and Reed 2013). After a few days in the field with our respondents we learned that the LAN house represented more than just a place to print or a place 
to recharge an ink cartridge. You can fax, scan, or modify a printed image. You can play computer games online, or get help printing out the police background check that you might need to apply for a job. And you might get help with your own computer from the LAN house operator.

There is no "average" LAN house but in many ways these establishments mirror storefront shops of other kinds in Brazil. In urban neighborhoods, the storefront is usually open to the sidewalk. The entire front of the store may be covered at night by a roll-up security door.

There is usually a sign over the door, sometimes commercially made of plastic but often a painted board or a plastic banner, generally mentioning the availability of copies (called "Xerox"), printing, and Internet. There is often a small counter where cash transactions are made, just like my first day's coffee shop, from which access to the computers in the shop is controlled and where more than one printer is stationed, usually one for black and white work and another for color. Smaller shops use multifunctional printers with fax capability; fancier shops will have dedicated fax machines as well as a cartridge refill apparatus and sometimes a large-format printer. Candy is usually available at the cash box (which had a cash register only in the franchise shops), and peripherals like pin-drives, inexpensive bluetooth speakers, or mobile phone cables are sometimes available. Signs on the walls show the prices of the services (one from São Paulo is reproduced in Table 1). The interior signs are sometimes echoed by two-sided letter boards, often emblazoned with a candy or beverage product logo, placed outside the store.

Table 1. LAN House Prices

\begin{tabular}{|l|c|c|}
\hline Internet & hour & $\mathrm{R} \$ 2.00$ \\
\hline Xerox Color & per side & $\mathrm{R} \$ 1.00$ \\
\hline $\begin{array}{l}\text { Xerox (Black and } \\
\text { White) }\end{array}$ & per side & $\mathrm{R} \$ .20$ \\
\hline $\begin{array}{l}\text { Expansion or } \\
\text { reduction }\end{array}$ & per page & $\mathrm{R} \$ .50$ \\
\hline $\begin{array}{l}\text { Printing (Black and } \\
\text { White) }\end{array}$ & per page & $\mathrm{R} \$ 1.00$ \\
\hline Printing Color & per page & $\mathrm{R} \$ 1.00$ \\
\hline Scanner & & $\mathrm{R} \$ 3.00$ \\
\hline Background check* & & \\
\hline
\end{tabular}

*Atestado de antecedentes, printed from federal police records online and required by job applicants. Author's translation. 
One, two, or three attendants staff the front desk. They know how to operate the local area network that links the LAN house computer terminals to the Internet. These people monitor access and customer usetime. They refill cartridges and are sometimes called on to provide help with training:

"Some of these guys can't find the " $\mathrm{A}$ " key on the keyboard," one Paulista LAN house operator told us.

We interviewed a respondent in a public housing complex about an hour north of São Paulo's downtown who told us that the LAN house she used was in the front room of one of the resident's apartments. We spent part of a morning at this shop. The operator, Choquinho, a 30something man with a shaved head and a bright smile, identified himself as a computer analyst. And a computer analyst, he told us, "has to analyze people, too."

Choquinho showed us around his converted-apartment $L A N$ house. He had a multifunctional copy and fax machine that would have been at home in any medium-sized office anywhere in the world. Shelving had been added to his apartment walls to hold a printer with a bulk-ink adaptor attached neatly to its right side with tubes the size of a ballpoint pen's ink tube, these tubes arced out of four ink reservoirs, each about the size of a pack of playing cards, carrying black, cyan, blue, and yellow ink to the printheads inside the printer. This arrangement was an especially tidy version of what we had seen at every LAN house, where one or more printers would have such work-around kits. A stack of blank CDs was available for making copies, and a bank of four computer CRTs was on tables along one of the walls:

Taís: So, you print a lot, here?

Choquinho: College work, copies of bills. . .

Taís: Do many have their own printers? Do they prefer to print here?

Choquinho: They come to charge cartridges.

Ingrid (a Choquinho client): I have a printer. I prefer to come here.

Choquinho: Actually, these women come and pay for classes. I teach a class here, mornings, sometimes. But it's really specific, what they want. The Internet, to control their kids. Generally, the kids go on Orkut [still a popular social networking website at the time] and the parents want a profile there. They want some tips and tricks. Always it's 'How do we find their messages? How do we see their MSN chats? What is their Facebook profile?' And they come for more: to see their kids' conversations, without leaving a trace. 
This statement points out something common to many household objects that becomes apparent when goods are explored as they move about in the exchange system. In the case of desktop printers, the object is more or less stationary and some negotiation has to happen to allow for, restrict, or encourage shared access. Consumer goods are often the objects of contention about where and to whom they belong in the home. In the case of computer apparatus at the time of our project, adolescents generally had much more cultural and social capital than their parents. These young people had both more knowledge about how computers work and a wider network through which they could gain access to other people (including other young people) who know how to install or repair machines. Young women like Francesca and Amélia were the ones sent out on printing or computer-related errands to make a print or to refill a cartridge. Their neighborhood mobility, sometimes with a piece of the assemblage in hand, afforded them access to the corner LAN house where they asked (as we watched Amélia do) how to fix a problem with a computer system that might be giving them trouble.

With a sample and a time frame as small as ours, we had not found a setting in which printers needed to be repaired, at least until the team's last few days in Recife. Sara and Tessa were on their way across the Ponte Gobernador Paula Guerra, the bridge that crosses the estuary separating the Pina neighborhood, where they were staying, from downtown Recife. They were halfway across the bridge, in heavy traffic, when their taxi broke down. While their driver stood outside to try to reach his dispatcher on his mobile phone, another cab driver saw them and offered the two researchers a ride:

"But you have to wait for me to move this box from the back seat," he said.

What was in the box? It was a printer made by our company sponsors, on its way to the repair shop. Ethnographic serendipity allowed the two women to conduct a crisp interview in the car with the driver who had rescued them from the bridge. (They learned that he considered the telephone customer service to have been quite good, though the suggested repair shop was-thankfully in this case-a bit far from his home).

Our team wrapped up its work and provided our client with an inperson report, including video clips and a slide presentation, at its headquarters. After we finished up our presentation, one of the Latin American regional directors asked his colleague to join him for a quick trip to a storage room in the building's basement:

"I want to bring something up here-wait for us a minute," he said. So, we did.

They returned with a printer, one with a bulk ink system already built in, a product that had been designed for and sold in one of the 
company's Southeast Asian markets. At one point, the company had joined similar firms in using patent protection lawsuits to limit the availability of unbranded, "knock-off" cartridges. It had also made technical modifications to make it difficult to refill company-approved ink cartridges. The LAN house, if it were seen at all, was seen as a competitor, not a possible customer. The LAN house already had a printer that would allow the company to step outside of the razor-and-blades business model.

Francesca shaking her ink cartridge, and our team's own experience with desktop printers, confirmed that desktop printer users around the world knew very well that ink cartridges were not designed to last long. The Brazilian work-around was drawing in ink from outside the printer company supply chains. We had visited a shop in São Paulo that imported and re-bottled printer ink for use in these work-around systems. Neighborhood ink cartridge refillers, like the one Francesca visited, used bulk ink, too. Boxes containing two-liter bottles of printer ink were stacked along one wall, and workers were re-bottling the stuff into smaller squeeze bottles to sell to LAN houses or to anyone with a bulk-ink workaround kit. Brazil would be a beachhead for the eventual redesign of this prototype printer and its eventual marketing throughout the Americas. And at that meeting, our original ethnographic question, which we had framed as 'What's going on with printing in C Class households in Brazil?' was changed to 'What might LAN house operators do with one of the company's purpose-built, bulk-ink printers?' Our Brazil team had a new opportunity to do new things.

\section{The LAN House, Again}

This second round of work began with a series of meetings to frame the scope of the new work. We would return again to Recife and São Paulo but this time we would recruit a sample of LAN houses. We discovered that SEBRAE (Serviço Brasileiro de Apoio às Micro e Pequenas Empresas), the Brazilian government organization responsible for economic development of small and medium businesses, already had an effort underway to support and train LAN house operators. We learned that Brazilian LAN house business models ranged from formal franchise operations like YesNet with multiple stores and fully-licensed independent owners in city centers, to informal, unlicensed entrepreneurs in favelas and small towns. Sara drew on her connections to identify two shops in São Paulo that had been operating under a franchise for more than five years and three smaller operations-one near a university that was about to expand to a second location. These LAN houses, and two other small shops, had owners in their late 20s and early 30s. All were near schools, government offices, or dense housing areas with lots of Paulista foot traffic. 
In Pernambuco, where incomes were generally lower, the team selected two informal (unregistered) shops at the edge of Recife and two others in high-traffic, downtown locations. These Recife locations had been open for at least two years. The plan was to offer each of these businesses a new printer, boxed up with specially bottled ink, ready to be filled into the printer's ink reservoirs, just as it would be if these units were to be sold in Brazil. Instructions in Portuguese were included inside the box. Our team would offer a cash incentive to encourage the $L A N$ house operators to keep track of how they used the machines.

Our client hoped to come to an understanding of the economic costs and benefits of using these new bulk ink printers. We were to engage the operators in a two-month usability trial to discover and discuss any problems or special benefits they encountered with their new machines. We were to be present when the shops unboxed and installed the printers, and we planned for follow-up meetings to capture printer use data. These tech-savvy operators were eager participants. As our team watched them unbox and set up their new tools, we found that they had been expecting an innovative solution, something new and better than their existing printers:

“There isn't much to discover," one said after installing the machine.

"It has the same look as a regular multifunctional printer."

Indeed, the form-factor of the unit was very nearly identical to other desktop multifunctional printers that could be found in Brazilian homes at the time. They were black plastic boxes with a lid on which to place an original for scanning or copying. Inside, were the paper transport and ink-head printing mechanisms while outside were openings for blank paper, power input and USB port, and a slot for printer output. On one side was a small control panel with three buttons: one to power on the unit, one to make a copy, and another to make a scan. All the LAN house operators kept these new bulk ink printers next to the operator's desk during the two-month test.

The printers were liminal in a way-both gift and an element in a monetary exchange with an expected pay-back to the researchers in the form of data and time given during interviews. The shops could do whatever they wanted to do with these printers after the two-month test; all said that they planned to keep them in their shops. All made an effort to record how much printing they were doing, how much of it was color and how much was black and white. All but two provided trustworthy data (the two that did not had been estimating their printing and writing it down just before team members arrived for follow-up visits). A subset of operators in each city also joined in a group interview to discuss their experiences at the end of the test.

The general pattern was puzzlement about one or two of the steps 
during installation of the operating software. There were some misunderstandings about a small lever on the ink reservoir that needed to be moved when the ink was being refilled, then correctly positioned to use the printer. These problems were addressed in later iterations of the product. The operators thought these printers had been designed for home use. São Paulo operators found them to be a bit slower than expected but they were fast enough for Recife, where speed did not emerge as a big concern. Not having to use messy refilling bottles, syringes and awkward tube-and-plastic-tank systems was appreciated. The new printer was sometimes used for high-quality color printing but served most often as a back-up printer for smaller color printing jobs. We managed to collect information on use and were able to calculate the income derived in all but the two shops that did a poor job of documenting their printing data.

The team mulled over the results after every field day, planning upcoming visits and managing our digital images and fieldnotes. We also reflected on the desktop printer as a sign marking the symbolic transition from a country with a wide gulf between social classes to a country with less economic and social distance among its residents. We noticed a kind of optimism in places like Recife, where jobs-once scarce-were now allowing families to do something that was exciting for young people, a little scary for adults, but overall, marked a kind of proud participation in Brazil's modernity. The cables may have been stretched between apartments but access to the web, taken for granted by wealthier Brazilians, was now within reach.

Some results of the work have been noted already: the highquality printer box was retained. A printer was tested. A few years after our work, the company began building a single bulk-ink model, similar to the one we tested. A year after that, a second line was added to accommodate another bulk-ink printer. The company began to market these money- and mess-saving printers throughout Latin America and eventually launched an array of similar printers in the U.S., where we were told they did not perform as well as they did in "Latin." By then, other manufacturers joined the bulk-ink parade but sales and market share for the manufacturer's new models in Latin America remained strong.

\section{The Value of Printers in Use}

Business-focused research of this kind is not generally designed to open up, challenge, or redesign the basic questions addressed in consumer and product work. Our respondents, like Choquinho and Amélia, may do it for and with us, demonstrating how local notions of class, gender, and age are implicated in technology access, use, and repair, pointing out realities beyond the product-focused view of a tactical field project. Broader 
questions of what desktop printers mean and for whom they mean it in Brazil did not occupy as much of our project time as they might have.

While much printed matter, academic effort, and public policy time is spent on the relationships among human beings and computers, little attention has been given to the desktop printer in its social and cultural contexts. But these objects, like other consumer goods, are social objects (Garabuau-Moussaoui and Desjeux 2000). Anthropologists take it for granted that consumer goods have a kind of social life (Appadurai 2006), participating in and shaping social life in systems of gift exchange or commerce, or in the case of printers and similar tools, as mediators of written communication. Writing or printing on paper is certainly a social business, changing the ways in which humans experience their households (Desjeux et al. 2000; Goody 1987).

The material artifact that appears after printing or writing affords the representation, reproduction, creation, or reshaping of human relationships, fixing and carrying messages, meaning, and value that move from hand to hand (Gitelman 2014). In Brazil, in this case, it may move from desktop printer, to hand, to the counter of the Loteria (lottery) office in Brazil where another hand receives the bills that can be paid only when presented in printed form. Complex printed receipts with specific instructions are provided to recipients of Bolsa Família payments, too (Hellman 2015). Printed matter of this kind, including detailed instructions about bringing printed family documents and electric bills (Hellman 2015: 15) mark the cycles of obligation to which Brazilian households are bound, cycles that rely on the accumulated technologies of paper making and transport, the accumulated techniques of ink formulation, the engineering knowledge required for its deposit on paper, and the managerial and marketing work of manufacturers. Requirements for Bolsa Família receipts, for example, suggests a level of importance for household printing that we had not clearly understood at the time. Printed documents are needed to pay bills and to access the Bolsa Família cash transfer program. Printing otherwise ephemeral family records are essential for Brazil's emerging middle-class households.

When we asked households to print out something, we were asking because our client was interested in seeing the print quality, and in understanding what our respondents thought of the quality of the print. We did not ask about the importance of printing in general at first, though later on, we came to understand the importance of printed household records as material ways of mediating state-household relationships. Among the households we visited, we heard about how desktop printers-or the LAN House-were put to work printing out such records.

The desktop printer has its roots in technology that emerged nearly a century and a half ago in tools designed to fix international telegraphic signals onto paper. These early machine-assisted inscriptions, 
made by a tool called the siphon recorder, brought electrically-charged ink and paper together to place tiny dots on moving strips of paper at the two ends of undersea telegraph cables. These marks on paper strips were often no more than a scrawl, squiggles that an "expert cable signaler... learns to interpret" (Brown 1903: 1076). Though the images from desktop printers today are better by far, there was-and is-no escaping the need for humans to figure out ways around the awkwardness of printing technology. In the contemporary capitalist context, such awkwardness may bounce back to the makers and sellers of that technology, who in this case, have decided to embrace the tensions caused by a peculiar mix of business models and printing technology to market and support a printer that does what the workaround did. The company is making and marketing its own bulk-ink printer and printer inks. This intrapreneurial effort came from a team of high-level regional executives who saw an opportunity and did new things about it. Despite the entrepreneurial literature's recent angst about defining what an entrepreneur is, this effort fits nicely with Schumpeter's influential ideas of what entrepreneurship is about.

Printed matter has not been displaced by the digital versions of text and images that appear on computer screens. For now, it is safe to say that neither the paperless office (Sellen and Harper 2003) nor the paperless home will become a reality in the near term, at least not as long as the rituals of bureaucracy demand material evidence of compliance with the disciplines of citizenship (Hull 2012). We will still look for paper trails and there will still be paperwork.

Was it the case in Brazil that the more important the exchange, the more fraught the transaction, the more likely it would be documented on paper? Had we attended more carefully to what was actually printed, and when, and for what purpose, we might have come near to some answers to the questions raised by that possible correspondence.

With some temporal and geographical distance from 2010 Brazil, it might have been both helpful and interesting to come to these households with questions about representational practices, generally. What is printed, and for whom? What is the itinerary of household printed matter? These questions might have provided a better understanding of how households write and use documents, or more broadly, how both carrot cake and a celebratory black-and-white banner, colored in to mark Francesca's birthday party, become signs of welcome in a São Paulo home.

With hindsight, we learned less about the specificities of printing and more about a technological assemblage as an enabler of relationships, tools designed to be part of sociability that would be profitable for our client. But the products made by the printer manufacturer, like all consumer goods, become domesticated, are given new meanings, and take 
on new patterns of use among households that are already acutely aware of the limitations-and expense-of these tools.

These broader anthropological questions about what households print in the context of political, environmental, and economic precarity may not be on the table when businesses are thinking about what they need to know to build market share in their overseas markets.

Or are they?

An awareness of Bolsa Família and the importance of Lula's political policies were part of the known context in which our sponsor's desktop printers made their way into households that could, usually for the first time ever, afford them. The company's bulk-ink printers have been doing well enough (and import tariffs are high enough) for these new printers to be made in Brazil. They are filling the market space between more expensive laser printers and ordinary, cartridge-driven desktop printers. Our client is no longer the only entrant in the bulk-ink printer world and work-around kits still have a place in the Brazilian market. The present moment in Brazil, for our client and for our research team, brings other concerns, concerns that point to the wider contexts that draw attention away from the product in itself and encompass a wider awareness of global realities.

My most recent communications with my colleagues in Brazil have been about the loss of Brazil's priceless national museum to a fire (arson perhaps, but unclear at this writing). That concern is coupled with a genuine fear for Brazil's - and researchers' - futures because of rising neo-fascist Brazilian politicians, among whom the current president is an archetype. Our main company contact, still a manager for consumer research for the Americas, said that its Latin American team has similar worries as post-election life in Brazil is experienced. Social scientists have documented the moral panic by adults, fueled by social-network savvy politicians, around Brazil's youth (Balieiro 2018; McCann 2018). This panic is used to support the rise of Brazil's current political spectacle panic that resonates with what we learned as we explored the perceived dangers of the Internet and the LAN house.

In fact, just before my almost unattainable cup of coffee on that first morning, I had been unpacking in my hotel room after my overnight flight to São Paulo when I faced these worries myself. I had turned on the hotel room television and was surprised to see an excited-and very large-congregation of evangelical Brazilian Christians listening in rapt attention to a sermon that, even with my poor Portañol, clearly referenced the globally corrupting and satanic influence of homosexuality on the moral fabric of the Brazilian family. Hearing and seeing this scene was not comforting for a gay anthropologist who had yet found breakfast and who was trying to focus on the narrow, tactical questions of a new research project. 
Are tactical questions ever only tactical? The present-moment concerns of our research sponsors and team members suggest that they are not. Asking where the ink goes-a very tactical question-can lead to a new business model and a new line of products. That's the kind of outcome that ethnographic venturing might hope to produce; these days, problems are even more global and intractable. The climate crisis of the post-Pleistocene, denied so strongly by the leaders of Brazil and the U.S. at the moment, demands that tactical questions be addressed as they relate to much larger issues. Business anthropologists, entrepreneurs, and intrapreneurs alike must now share these Brazilian concerns for they have become global. We all face the shared necessity of widening the scope of our questions and re-tooling our workarounds if we are to hope for a world in which Amélia, Francesca, Choquinho, and all of us might enjoy without panic the rituals and annoyances of printed and lived sociability.

\section{References}

ABEP (Associação Brasileira de Empresas de Pesquisa) 2008. Critério de Classificação Econômica Brasil.

http://www.abep.org/Servicos/Download.aspx?id=07, Accessed August $5,2018$.

Agar, M., 2013. The Lively Science: Remodeling Human Social Research. Minneapolis: Hillcrest Publishing Group.

Arias, M.A. and Y. Wen. 2015. Recovery from the Great Recession Has Varied Around the World. The Regional Economist (St. Louis Federal Reserve Bank).

https://www.stlouisfed.org/ /media/Publications/RegionalEconomist/2015/October/recession.pdf, Accessed August 5, 2018.

Blanco, F., F. de Holanda, B. Filho and S. Pessôa. 2011. Brazil: Resilience in the Face of the Global Crisis. In M. K. Nabli, ed. The Great Recession and Developing Countries. Washington, DC: The World Bank. https://doi.org/10.1596/9780821385135 CH03

Briody, E. and K. Erickson 2017. Success Despite the Silos: System-Wide Innovation and Collaboration, In M. McCabe, ed. Collaborative Ethnography in a Business Environment. New York, NY: Routledge.

Brown, S. G., 1903. Automatic Relay Transmission for Long Submarine Cables, Journal of the Society of Telegraph Engineers: Including Original Communications on Telegraphy and Electrical Science 31: 1075-1076. https://doi.org/10.1049/jiee-1.1902.0050

Bufete, T., 2018. The High Cost of Wasted Printer Ink. Consumer Reports August 17, 2018. https://www.consumerreports.org/printers/the-high- 
cost-of-wasted-printer-ink/, Accessed August 20, 2018.

D. Desjeux, S. Alami, I. Garabuau-Moussaoui and S. Taponier. 2000. Le jeu de la proximité et de la distance dans la communication quotidienne, In I. Garabu-Moussaoui and D. Desjeux, eds. Objet banal, objet social: Les objets quotidiens comme révélateurs des relations sociales. Paris, France:

L'Harmattan, 214-238.

da Silva, L.A. and Gushiken, Y. 2010. LAN house: novos mapas de acesso digital na cidade de Cuiabá, Conexão-Comunicação e Cultura, 9(18): 75-88

Balieiro, F de F. 2018. 'Não se meta com meus filhos': a construção do pânico moral da criança sob ameaça. Cadernos Pagu, Vol. 53. http://www.scielo.br/scielo.php?script=sci arttext\&pid=S010483332018000200406\&lng=pt\&tlng=pt, Accessed September 26, 2018. https://doi.org/10.1590/18094449201800530006

Denny, R. M. and Sunderland, P. L. eds., 2016. Handbook of Anthropology in Business. New York, NY: Routledge. https://doi.org/10.4324/9781315427850

Desjeux, D., 2016. The Itinerary Approach of a Business Anthropologist: Between Mobility, Diversity and Networks, Journal of Business Anthropology 5(1): 64-76. https://doi.org/10.22439/jba.v5i1.5215

Desjeux, D. 2004. The Itinerary Method: Comparing Intercultural Daily Life, Consumers, Commodities and Consumption 5(2): 1-13.

Fauna. 2014. Goodby WangBa: The Rise and Decline of Internet Bars in China, China Smack. https://www.chinasmack.com/goodbye-wangba-therise-decline-of-internet-bars-in-china, Accessed August 30, 2018.

Garabuau-Moussaoui, I. and Desjeux, D. 2000. Objet banal, objet social: Les objets quotidiens comme révélateurs des relations sociales. Paris, France: L'Harmattan.

Gitelman, L. (Editor) 2014. Paper Knowledge: Toward a Media History of Documents. Durham, NC: Duke University Press.

https://doi.org/10.1215/9780822376767

Goody, J. 1987. The Interface between the Written and the Oral. Cambridge, UK: Cambridge University Press.

Graeber, D. 2015. The Utopia of Rules: On Technology, Stupidity, and the Secret Joys of Bureaucracy. Brooklyn: Melville House.

Hellman, A. G. 2015. How Does Bolsa Familia Work? Best Practices in the Implementation of Conditional Cash Transfer Programs in Latin America and the Caribbean. Inter-American Development Bank Technical Note 856.

de Araujo, H, M. N. Reinhard and M. A. Cunha 2018. Servicios de gobierno electrónico en Brasil: un análisis a partir de medidas de acceso y competencias de uso de Internet, Revista de Administração Pública 52(4): 
676-694, July/August. https://doi.org/10.1590/0034-7612171925

Hertz, E., 1998. The Trading Crowd: An Ethnography of the Shanghai Stock Market (Vol. 108). Cambridge, UK: Cambridge University Press. https://doi.org/10.1017/CB09781139166850

Hull, M.S., 2012. Documents and Bureaucracy. Annual Review of Anthropology 41: 251-267. https://doi.org/10.1146/annurev.anthro.012809.104953

Karsten, M.M.V., 2019. Short-term Anthropology: Thoughts from a Fieldwork Among Plumbers, Digitalisation, Cultural Assumptions and Marketing Strategies, Journal of Business Anthropology 8(1): 108-125. https://doi.org/10.22439/jba.v8i1.5718

Kim, C., Self, J.A. and Bae, J., 2018. Exploring the First Momentary Unboxing Experience with Aesthetic Interaction, The Design Journal 21(3): 417-438. https://doi.org/10.1080/14606925.2018.1444538

Moeran, B., 2005. The Business of Ethnography. Berg Publishers.

McCann, B., 2018. Brazil's New Right, Dissent 65(2): 114-121. https://doi.org/10.1353/dss.2018.0035

Mújica, O.J., Vázquez, E., Duarte, E.C., Cortez-Escalante, J.J., Molina, J. and Silva Junior, J.B.D., 2014. Socioeconomic Inequalities and Mortality Trends in BRICS, 1990- 2010. Bulletin of the World Health Organization, 92: 405412. https://doi.org/10.2471/BLT.13.127977

Nemer, D. and Reed, P., 2013. Can a community technology center be forprofit? A case study of LAN houses in Brazil. In Proceedings of the CIRN 2013 community informatics conference. Prato, Italy, October. https://www.researchgate.net/profile/David Nemer/publication/29134 6091 Can a community technology center be forprofit A case study of LAN houses in Brazil/links/56a13ad408ae2afab 882936e/Can-a-community-technology-center-be-for-profit-A-casestudy-of-LAN-houses-in-Brazil.pdf Accessed August 25, 2019.

Santos, C. 2014. Pernambuco: The New Locomotive of the Northeast, Oxygen 23 (June) http://oxygen.enel.com/category/23-brazil/, Accessed August 24, 2018

Scheper-Hughes, N. 1993. Death without Weeping: The Violence of Everyday Life in Brazil. Berkeley: University of California Press.

Sellen, A.J. and Harper, R.H., 2003. The Myth of the Paperless Office. Cambridge, MA: MIT Press.

Sunderland, P. and R. Denny, 2011. Consumer Segmentation in Practice. In D. Zwick and J. Cayla, eds. Inside Marketing. Oxford, UK: Oxford University Press, 133-161.

Tett, G., 2009. Fool's Gold: How the Bold Dream of a Small Tribe at JP Morgan Was Corrupted by Wall Street Greed and Unleashed a Catastrophe. 
New York, NY: Simon and Schuster.

Victora, C.G., Aquino, E.M., Leal, M.D.C., Monteiro, C.A., Barros, F.C. and Szwarcwald, C.L. 2011. Saúde de mães e crianças no Brasil: progressos e desafios, Saúde no Brasil 2,

http://dms.ufpel.edu.br/ares/bitstream/handle/123456789/279/15\%2

0Sa\%FAde\%20de\%20m\%E3es\%20e\%20crian\%E7as\%20no\%20Brasil\%

20progressos\%20e\%20desafios.pdf?sequence=1, Accessed July 12, 2019.

Ken C. Erickson, Ph.D., began writing about material culture in the late 1970s. Early work explored cowboy apparel as found in the University of Wyoming's photo archives and reported historical archaeology along the Union Pacific railroad with archaeologist William Fawcet. Erickson was on the Garden City, Kansas team of Changing Relations project (see for example Lamphere, Stepick and Grenier's 1994 edited volume, Newcomers in the Workplace). After doctoral research (U. Kansas) on beef packing shop-floors, he formed the Center for Ethnographic Research at U. Missouri-Kansas City. This led to consumer ethnography with Hallmark Cards and eventually business venturing in two enterprises, first with Kansas City colleagues (Ethnographic Research LLC) and another, Pacific Ethnography, with an international team ("Able to Fly" in Sunderland and Denny's 2014 Handbook of Anthropology in Business is a published example). Erickson is now a clinical faculty member in the International Business Department at the University of South Carolina's Darla Moore School of Business. 